\title{
ASSESSMENT OF PUBLIC EXPENDITURE EFFICIENCY: A REVIEW
}

\author{
Wong Sing Yun ${ }^{1+}$
}

${ }^{1}$ Faculty of Business, Economics and Accountancy

Universiti Malaysia Sabah

+ Corresponding author: yutina707@yahoo.com

\begin{abstract}
Public spending is considered an important tool in a government's continuous efforts to improve the delivery of the public sector and achieve growth objectives. The increasing demand for higher expenditures may create a tax burden and pressurised the budgetary allocation. This leads to the rising concern to evaluate the efficiency and effectiveness of public expenditure. A highly efficient public sector will likely be able to produce more outputs with less spending on inputs. Hence, the primary aim of this paper is to provide a comprehensive review of the growing literature on public expenditure efficiency. Against this background, an extended review will be discussed on the determinants that influence the efficiency of public spending. As such, the objective of this paper can be summarised to address the following key questions. Firstly, how to measure the efficiency and effectiveness of public expenditure? Secondly, what are the determinants that influence the efficiency of public spending? The answers to these questions will help solve the recent problem of budget constraints faced by policymakers.
\end{abstract}

Keywords: Review, Public Expenditure, Efficiency, Assessment, Determinants. JEL Classification: H50, O5, O21, P43, P47.

Received 20 October 19. Revised 29 December 19. Accepted 10 January 20.

\section{Introduction}

In the past few decades, there had been an enormous growth in public expenditure in many countries. The increasing pressures for more public spending were most likely stemmed from demographic trends and globalisation. With the growing demand for public expenditure, it would not be advisable to cut public spending. However, the rising public expenditure may possibly strain public resources. Hence, it would be fundamental to ensure that public resources are utilised efficiently and effectively. In other words, it is imperative that public spending is used efficiently to improve long-term economic growth. As such, one of the primary concerns is the need to raise the efficiency of public expenditure. Efficient public spending indirectly increases the value of money in achieving growth objectives, thus making most of the available scarce public resources.

Fox (2002) highlighted that assessing public sector performance is deemed essential to maintain a prosperous economy and promote economic growth. Efforts to assess the efficiency of public spending have since become a subject of the growing literature, which proposes that the measurement of public expenditure efficiency will provide room for future improvement in public policy. In evaluating the efficiency of public spending, Wang and Alvi (2011), Esanov (2009), and Hauner and Kyobe (2008) adopted the Data Envelopment Analysis technique. They typically measured the efficiency of public expenditure by evaluating the relative efficiency of the input in producing output. Meanwhile, Tanzi and Schuknecht (2000), Gupta and Verhoeven (2001), and Afonso et al. (2005) contributed to the literature by measuring public sector efficiency in relating public expenditure to its respective targeted socio-economic 
indicators. Other studies related government expenditure to economic growth in investigating the efficiency of public spending.

A comparison of the cross-country public expenditure efficiency analyses poses an important question about the missing factors that could potentially explain the public spending variation. In the more recent literature reviewed, we find papers sought to examine these determinants that explain the efficiency of government expenditure. A closer examination of the public expenditure efficiency by such literature reveals additional factors. It is assumed that a better understanding of the determinants of government efficiency will help improve public sector performance (Esanov, 2009). Public economists have long been interested in assessing the performance of the public sector and identify the determinants that could explain the variations, both across countries and over time (Wang \& Alvi, 2011).

The rest of this paper will be structured as follows. Section 2 briefly presents a conceptual framework to evaluate the efficiency and effectiveness of public expenditure. Section 3 discusses the present literature that analyses the efficiency of public spending. Section 4 provides a short discussion on the literature that examines the efficiency of public spending by relating it to economic growth. Section 5 elaborates the past findings of the determinants that explain the variations of public spending. Section 6 summarises the review of the existing literature and proposes future studies that can be conducted.

\section{Conceptual Framework for Efficiency and Effectiveness of Public Sector}

The study of the efficiency and effectiveness of public expenditure performance attempts to link the inputs, outputs, and outcomes. Farrell (1957) addressed the main question as how to measure efficiency and highlighted its relevance for economic policymakers. Figure 1 shows a conceptual framework of efficiency and effectiveness. The conceptual framework illustrates the relationship between input, output, and outcome. The greater the output produced with a lower given input reflects a highly efficient public sector. Effectiveness relates the input or the output to the final outcomes. The outcome is commonly referred to as a growth objective. It should be noted that efficiency and effectiveness are likely to be influenced by external environmental factors. The analysis of efficiency and effectiveness of the public sector will demonstrate the success of a nation in using the scarce resources to achieve growth objectives. The importance of this analysis has attracted many researchers to measure the efficiency and effectiveness of public spending. In addition, some papers have sought to conduct a crosscountry evaluation to uncover further interesting insights into the key drivers of public spending efficiency. 


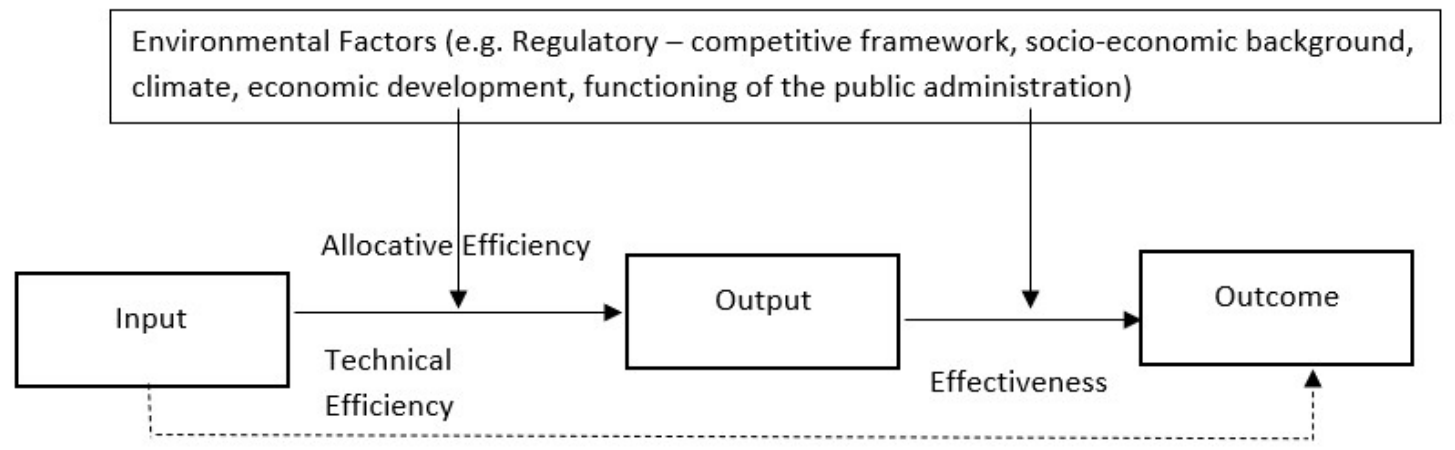

Figure 1 Conceptual Framework of Efficiency and Effectiveness

Source: Mandl et al. (2008)

\section{Evaluation of Government Expenditure Efficiency}

In dealing with the increasing pressure for higher public expenditure to meet increasing demand, it becomes ever more fundamental to improve the efficiency and effectiveness of public spending. With this in mind, many researchers analysed the efficiency of public spending in various countries. Some offered cross-country comparisons of the efficiency and effectiveness of public spending. Many studies assessed the efficiency of public spending by using the Data Envelopment Analysis (DEA) (Afonso et al., 2005; Dutu \& Sicari, 2016; Esanov, 2009; Hauner \& Kyobe, 2008; Wang \& Alvi, 2011). The DEA approach is based on a linear combination of input and output. It is used to measure the efficiency relative to a frontier.

Before adopting the DEA approach, Afonso et al. (2005) computed public sector performance indicators and public sector efficiency to provide a clear proxy in measuring the efficiency of public spending for over 23 industrialised countries. The input-output efficiency of the public sectors was then measured via the DEA approach. The DEA result revealed the prevalent declining marginal products of public spending. They also managed to show that the small public sectors in certain countries posted higher efficiency than those in industrialised countries. The result suggests that the size of the government might have become too large in these countries. However, countries with large public sectors demonstrated equal income distribution. Such finding leads to an important question of whether a high level of government spending is required to ensure the growth of a country. With increasing populations, more public spending may be demanded, which would likely burden the government. However, will the move to increase the public expenditure likely to be sufficient?

In another much recent study, Afonso et al. (2008) extended their analysis of the efficiency of public expenditure by empirically examining its role in the redistribution of income. By using DEA as the tool, they found that redistributive government expenditure had a significant effect on income distribution. Dutu and Sicari (2016) similarly applied the DEA approach to assessing the efficiency of public spending, specifically the welfare spending, in a sample of OECD countries. A wide dispersion in efficiency measures across the OECD countries was shown in their cross-country comparison. Similarly, Herrera and Pang (2005) applied the DEA approach to assessing the efficiency of public spending on education and health care spending for 140 developing countries. They found that efficient spending was associated with lower expenditure levels. By utilising the same DEA approach, these studies have generally highlighted the essential need to evaluate the efficiency of public expenditure. These studies ascertain that the hypothesis of a greater level of public expenditure may not necessarily lead to greater efficiency. 
The commodity boom cycle from 2003 to 2008 had increased the world prices for oil and natural gas. This allowed the resource-rich former Soviet republics, such as Azerbaijan, Kazakhstan, and Russia, to dramatically increase their government spending between the years of 2000 and 2007. Esanov (2009) found striking differences in the overall spending efficiency when he compared their spending efficiency with that of the more advanced transitional countries and some developed countries. Esanov also illustrated that better cost-effectiveness did not necessarily translate into better systemic efficiency overall. Most of Esanov's findings appeared to support the argument that increased spending does not bring about additional efficiency, as in the case of the former Soviet republic. Hauner and Kyobe (2008) offered an even more resounding conclusion that the higher expenditure relative to GDP tends to be associated with lower efficiency. In their study, Hauner and Kyobe compiled the first large cross-country panel dataset of public sector performance and efficiency encompassing 114 countries from 1980 to 2006 . These past studies illustrate that the level of government expenditure is not closely associated with the efficiency of spending, supporting the hypothesis.

On a separate note, Wang and Alvi (2011) examined the relative efficiency of government spending in seven Asian countries from 1986 to 2007. By using the DEA approach, they provided estimates of the government spending inefficiency and further explored the factors significant for such inefficiencies. Their key finding suggests the following. Firstly, public spending efficiency tends to decline when there is an increase in private economic activities. Secondly, government expenditure will be relatively efficient during the period of recessions. They extended their study from a mere analysis of the relationship between the level of government spending and its efficiency towards seeking the underlying reasons for the inefficiency of public expenditure. This implies that other factors have a large effect on the efficiency of public spending instead of the level of spending.

The measurement of the costs of public activities and the assessment of its efficiency via outcome measures are still considered thorny issues that require to be resolved. However, academics and economists have made some progress in this regard. Afonso et al. (2010) analysed public sector efficiency in the new member states of the EU by comparing them to that in the emerging market. Efficiency scores and rankings were computed by adopting a range of measurement techniques. They found that the public spending efficiency across the EU member states was rather diverse in comparison to that of the emerging markets in Asia. Nonetheless, it became apparent that many of the new member states and other emerging markets can still consider increasing the efficiency of public expenditure by improving the outcomes and restraining resource use. The analysis of the composite public sector performance and efficiency scores revealed that countries with lean public sectors and public expenditure ratios tended to be the most efficient.

Ouertani et al. (2018) provided a conflicting finding in explaining the effect of the size of public expenditure on its efficiency. They concluded that public expenditure appeared to be inefficient, on average, in Saudi Arabia, based on the non-parametric DEA analysis. This implies that the increase in government investment or enhancement of budget does not produce significant improvement to the output or outcome. However, Ouertani et al. noted that the use of the non-parametric DEA approach might have misled the results in the presence of outliers and misspecification of inputs and outputs. So, they applied the DEA-bootstrap analysis in the second stage of their analysis. The result of the DEA-bootstrap analysis revealed that the size of the government positively affected the public expenditure's efficiency. 
Most past studies have employed the DEA approach to examine the efficiency of government spending. However, others have utilised a different form of non-parametric methods known as the Free Disposal Hull (FDH) technique. Distinct from DEA, the FDH imposes the fewest form of restrictions and follows a stepwise approach to create the efficiency frontier. FDH was adopted in other studies, such as Gupta and Verhoeven (2001), Afonso et al. (2005), and Moreno-Enguix and Bayona (2017) in their efforts to derive the performance index of the government expenditure. In their study, Afonso et al. (2005) applied the FDH framework. The application of the FDH approach allows one to determine the minimum level of input required to attain a given level of output or outcome, thus, enabling the identification of presence of any production inefficiency.

Gupta and Verhoeven (2001) applied the FDH approach to empirically assess the relative efficiency of production units in a market environment and investigate the efficiency of public spending in 37 African countries. The regression analysis showed a positive relationship (with constant elasticity) between government expenditure on education and health care and the indicators of the educational attainment and health output. The empirical evidence of this study demonstrated that although an increase in government expenditure generated benefits in the form of improved output, the increase was independent of the level of spending. The degree of inefficiency was found to increase rapidly with the level of spending. The alternative approach adopted by this study confirmed the hypothesis of an insignificant relationship between the level of government spending and its efficiency.

In their analysis, Afonso et al. (2005) applied the FDH approach to measure the efficiency of public spending. The FDH technique adoption allowed the identification of inefficiency in terms of input efficiency and output or outcome efficiency. The analysis conducted on the sample of 23 OECD countries demonstrated that the non-EU OECD countries had more efficient public spending. Unlike other studies, their finding pointed out that small governments tended to show a better result. Another study that applied the FDH approach to assessing public expenditure efficiency was Moreno-Enguix and Bavano (2017). They assessed the efficiency of government spending of 35 economies. Their finding demonstrated that the differences in efficiency were very much pronounced across countries, thus suggesting that the size of government might be too large in many industrialised countries. In addition, a higher level of public expenditure efficiency was likely to be associated with higher levels of GDP per capita. From the findings outlined above, one should recognise the absence of studies that analysed the factors affecting the efficiency of public expenditure and the nexus between government spending and economic growth.

It is clear from the reviewed literature that by using the non-parametric DEA analysis, most studies have found that public expenditure was rather inefficient, especially in industrialised countries. This implies that the increase in government expenditure may not generally improve the output or outcome as hoped by many. The existing literature indicates that an increased level of public expenditure may not necessarily lead to an improvement in its efficiency. In addition, most of the cross-countries studies conducted have unanimously revealed the diverse differences in the public expenditure efficiency found in these countries, which led to the growing literature on examining the determinants that influence public spending efficiency. In Section 5, we will examine these findings that sought to answer the remaining question as to what factors influence public spending efficiency. 


\section{Government Expenditure - Economic Growth Nexus}

Studies on the efficiency of public spending management tend to be related to other economic variables. There is growing academic literature on the effects of public expenditure on economic growth and macroeconomic stabilisation. These include works by Saunders (1985), Landau (1986), Hansson and Henrekson (1994), Fan et al. (2000), Alfranca and Galindo (2003), Chen (2006), Wu et al. (2010), Afonso and Alegre (2011), Taiwo and Abayomi (2011), Carboni and Medda (2011), Salih (2012), Odhiambo (2015), and Kimaro et al. (2017). These studies attempted to bridge the gap in the link between public expenditure efficiency and economic growth as an outcome.

In light of insufficient evidence to assess the effect of government activity on economic performance, Saunders (1985) presented an analysis of the growth of government in OECD countries and linked it with macroeconomic performance. The observed performance of the economic indicators from the analysis exhibited a relationship with the size and growth of public-sector activity. Landau (1986) demonstrated a noticeable negative influence of government consumption expenditure on economic growth. Meanwhile, government education spending was found to be inefficient in generating actual education. In addition, government capital development expenditure appeared to have an insignificant influence in accelerating economic growth. The result of his analysis refuted the hypothesis of a positive contribution of government expenditure to economic growth. However, some researchers argued that the finding suffered from methodological problems.

Researchers who argued the invalidity of previous findings include Hansson and Henrekson (1994). They introduced a new method to resolve the ambiguous findings of the relationship between government expenditure and economic growth. A production function approach with disaggregated data from 14 OECD countries and 14 industries were used to mitigate the methodological problems. This resulted in a distinct and consistent finding that demonstrated that different types of public spending generally produced varied effects. For example, consumption expenditure and transfers invariably produced a negative effect on the growth rate of total factor productivity. On the other hand, education expenditure appeared to generate a positive impact on the total factor productivity growth. The robust finding also indicated that the impact of government expenditure worked better on the total factor productivity rather than on the marginal productivity of labour and capital.

Meanwhile, Fan et al. (2000) extended the analysis by developing an estimation on the direct and indirect effect of the different types of public spending. Their finding contributes to the literature by focusing primarily on the composition of government expenditure. The direct effects of the public spending referred to the benefits the poor are receiving through employment programs. Meanwhile, indirect effects arise when government investments stimulate growth, which further leads to greater employment and income-earning opportunities. The result generated from the simultaneous equation model showed the need for the government to prioritise certain expenditure to achieve optimal growth. For example, the analysis of the Indian state-level data from 1970 to 1993 demonstrated that the Indian government should increase their public investments in the rural and agricultural sector to reduce rural poverty. The finding suggests the significance of the composition of government expenditure rather than the level of its allocation.

The growth effects of public spending have become a highly debatable research topic in economics. Countries with a large share of productive public expenditure have reached higher economic growth, while those with a smaller share tend to achieve lower growth. As such, a 
large share of productive public spending has been positively associated with economic growth. Against this background, Chen (2006) analysed the optimal composition of government expenditure. By using an endogenous growth model, Chen found that the indirect impacts of optimal public spending composition generated strong growth effects. In fact, the large growth effect generated through the optimal public investment had created implications for the East Asian economic growth miracles. These effects very likely emerged due to the change induced on the marginal utility of consumption that prompted governments to redistribute budgets. Chen's finding supports Fan et al.'s (2000) work and presents robust evidence that the composition of public expenditure plays an important role in improving economic growth.

The relationship between the composition of expenditure and economic growth was further pursued and focussed in the recent development of the endogenous growth theory. Fiscal policy was particularly viewed as a tool that could significantly influence production by changing the pattern of consumption and investment in an economy. Against this background, Afonso and Alegre (2011) empirically investigated whether any reallocation of the government budgetary components could enhance the long-term economic growth in a set of 15 EU countries. A dynamic panel data model of the 15 EU countries from the years 1971 to 2006 was estimated to compute the long-term relationship. They found a negative impact of public consumption and social security contributions on economic growth. However, a positive effect of public investment on economic growth was found.

Publicly provided goods are deemed to contribute positively to aggregate production. A few studies observed that an increase in government expenditure was accompanied by a decline in income growth. An extended neoclassical growth model was later developed by Carboni and Medda (2011) to address such ambiguous findings. In the pursuit of the relationship between public expenditure and economic growth, a non-monotonic relationship between them was shown. Such a relationship, however, disappeared during the process of convergence. In addition, fiscal policy was considered to have a considerable influence on the level of capital and output. Any changes in the spending structure may lead to different growth rates. This had induced the government to redistribute allocations between the less and more productive sectors to yield maximum positive outcomes.

Although the current literature has firmly established the significance of the composition of public expenditure on economic growth, none of the previous studies attempted to provide evidence of the direction of causality between public spending and economic growth. A reexamination of the relationship between government expenditure and economic growth through granger causality test was then explored by Wu et al. (2010). By utilising panel data of 182 countries, their empirical results supported the hypothesis that government spending is helpful to economic growth regardless of its size. A bidirectional causality was confirmed between government activities and economic growth. Similarly, Odhiambo (2015) offered empirical evidence that showed bidirectional causality between government expenditure and economic growth under the auto-regressive distributed lag model (ARDL) approach.

However, Salih (2012) refuted the Keynesian theory in explaining the relationship between economic growth and government expenditure. The Keynesian theory states that an increase in government spending should be followed by an increase in GDP. This suggests a unidirectional causality from government spending to economic growth. Taiwo and Abayomi (2011) reported a positive relationship between government expenditure and real GDP. Using the econometrics model with ordinary least square (OLS) in Nigeria from 1970 to 2008, they recommended that the government should emphasise promoting the efficiency of its allocation. Findings from 
these studies have largely confirmed the existence of a causal relationship between public expenditure and economic growth.

Most studies have demonstrated a positive nexus between public expenditure and economic growth by focussing on its composition. However, a number of researchers have taken a step back by testing the common belief that the size of public expenditure may lead to economic growth. Motivated by the common belief, Kimaro et al. (2017) presented solid evidence that government expenditure accelerated economic growth of low-income countries in Sub-Saharan Africa. However, government efficiency did not appear to speed up the impacts of government spending on economic growth. They concluded that government efficiency in Sub-Saharan African low-income countries was not effective in the allocation of public spending to enhance economic growth. Based on their empirical findings, Kimaro et al. recommended that the government of Sub-Saharan African low-income countries should consider expanding their public sectors to boost economic growth. Empirical results by Alfranca and Galindo (2003) on 19 OECD countries similarly reported that the increase in government expenditure generally led to larger economic growth.

The voluminous findings that link public expenditure with economic growth or other economic performance indicators reflected a diverse insight amongst different countries. In addition, certain studies have demonstrated the importance of public spending composition where public investment in certain sectors has generated a significant positive impact. Other studies reported either a negative effect or an insignificant influence on economic growth. The diverse finding leads to the next question: 'what are the underlying factors that may influence the efficiency of public spending?' Public sector performance may be affected by various environmental factors, such as economic factors, demographic factors, etc. The extensive literature reviewed has presented a large gap about what explains the efficiency of government expenditure since its composition and level of spending have failed to provide a general consensus.

\section{Determinants Influencing the Efficiency of Government Expenditure}

Motivated by the existing literature gap, additional studies extended the analysis by seeking the determinants that could explain the expenditure efficiency. One of these studies includes Afonso et al.'s (2010), which sought empirical evidence of the public sector efficiency in the new member states of EU and compared it with that in the emerging market. They extended the analysis to identify the exogenous factors that could explain the efficiency of public expenditure. Econometric evidence via the Tobit regression analysis revealed that higher economic, civil service competence, education levels, as well as the security of property rights, facilitated the prevention of inefficiencies in the public sector. Meanwhile, other factors, such as international trade openness, trust in politicians, and transparency of the political system, failed to deliver a significant influence on the public spending efficiency.

Similarly, Esanov (2009) examined the possible determinants of the efficiency of public spending in Russian regions. The efficiency score was regressed on a host of environmental variables. Esanov posited the following. Firstly, higher income (as shown by the per capita gross product) may be associated with better outcomes. Secondly, the increase in income may similarly increase the cost of public services while reducing public spending efficiency. His study supported the first hypothesis. A significant positive correlation between income and public expenditure efficiency was found. However, little evidence was found to support that other factors, such as climate, water pollution or population size, may adversely affect efficiency. Since the Russian regions are rich in oil and gas resources, it was not entirely 
surprising that there was a negative correlation found between the oil sector and efficiency score.

Hauner and Kyobe (2008) contributed to the literature on public spending efficiency by examining the policy and environmental factors of efficiency. The scores of efficiency were linked to the possible factors of economics, demographics, geography, and institutions. Univariate and multivariate regressions were run in their analysis. In addition, both fixed and random effects with system GMM estimators were alternately performed. The estimation evidence showed that institutional, demographic, and geographical factors mattered in explaining the efficiency of public spending. For example, a relatively larger youthful population reduced the performance and efficiency in the education sector. In contrast, a higher population density was found to improve performance and efficiency by allowing returns to scale. Also, the economic determinant of income per capita was posited in that higher income is associated with better outcomes.

In an attempt to model the determinants of government expenditure, Moreno-Enguix and Bayona (2017) tested the association of public spending efficiency with other key socioeconomic indicators. They revealed that a higher level of government expenditure efficiency was associated with significantly higher levels of GDP per capita, democracy, public trust in politicians, judicial independence, and a lower level of corruption. A significant finding was similarly reported between demographic factors and public spending efficiency. A higher level of population density was linked to a significantly lower level of efficiency. A larger public sector size was also found to be closely related to a significantly higher level of overall efficiency. The empirical results imply that it is considered necessary to apply policy reforms and increase investments to enhance economic and social performance.

Ouertani et al. (2018) applied the sampling technique and the DEA-bootstrap technique to identify the environmental variables that could explain the inefficiency of Saudi Arabia government spending. The estimation indicated that economic factors, such as inflation, had a significant negative effect on public expenditure efficiency, specifically in the infrastructure sector. This finding is consistent with Fonchamnnyo et al.'s (2016) work. The problem of inflation resulted in economic instability. This could be the reason for the negative impacts of inflation on spending efficiency. Apart from this, the empirical estimation also revealed that urbanisation demonstrated a significant positive influence on public spending efficiency, especially in the three sectors of education, health, and infrastructure.

On the other hand, unemployment had a negative effect on the efficiency of government infrastructure spending. GDP growth and broad money were found to exhibit a negative influence on public health care spending. Fonchamnnyo et al. (2016) advocated the same conclusion by implying that economic growth leads to improvement in efficiency.

In contrast, Gupta and Verhoeven (2001) dismissed that an increase in public spending generally leads to improvement of outcomes. Ouertani et al. (2018) found a positive association between public expenditure and its efficiency. However, this finding is not entirely surprising because Xu et al. (2003) reported a similar finding earlier. Wang and Alvi (2011) assessed the factors significant in explaining the inefficiency of public spending by using the Tobit regression and extreme bounds approach. They found that the inefficiency of government expenditure declined with an increase in private economic activities, such as consumption, investment, and exports. Secondly, political factors, such as corruption, contributed to the inefficiency of public expenditure. Lastly, government expenditure was found to be relatively efficient during the period of recession. The evidence presented by these studies largely affirms 
the significance of the economic, demographic, and political determinants, such as population size and density, inflation, unemployment, economic stability, transparency in spending, growth of private economic activities.

The literature has identified possible factors that influence and explain public expenditure efficiency. Environmental factors that comprise economic, demographic, geographical, and institutional factors, could affect the efficiency and effectiveness levels of public spending, highlighting the need to take into account these various circumstances when considering the efficiency analysis of government expenditure. Mandl (2008) stated that the neglect of such factors could lead to bias in the measurement of efficiency and effectiveness. Secondly, such factors can be effective instruments in enhancing efficiency and effectiveness. The understanding of the factors will improve budgetary provision in the future. The growing interest in examining the determinants of public expenditure reflects the limited and sparse number of studies to explain the extent of these determinants in explaining the public expenditure efficiency and the importance of this topic.

\section{Conclusion}

The topic of the efficiency and effectiveness level of government expenditure has become a highly pursued topic, as evidenced by the growing literature. This paper provides an in-depth explanation of the concepts of the effectiveness and efficiency level of public spending. In addition, the relevant literature on measuring the effectiveness and efficiency level of government spending reflects the importance of allocative efficiency. The existing literature argues about the common belief of the significance of the size of public expenditure in influencing its efficiency. Much literature has shed light on the significance of the composition of the allocation and the influence of other determinants, suggesting that factors that influence the efficiency of government expenditure require an in-depth study. The literature reviewed further highlights that the efficiency of public expenditure is influenced by environmental factors, such as economic, demographic, geographical, and institutional factors. However, these findings remain relatively diverse across different countries and different spending areas. As such, future studies on individual spending areas may seem to be more promising than total spending. The reviewed literature further points out the gap on the extent of these factors in influencing public expenditure efficiency. In addition, an in-depth study of a specific country may be more useful to allow better identification of factors influencing public expenditure efficiency. Such estimates will help policymakers develop a better fiscal policy with a higher efficiency and effectiveness level. 


\section{References}

Alfranca, O. \& Galindo, M. A. (2003). Public Expenditure, Income Distribution, Growth in OECD Countries. International Advances in Economic Research, 9(2), 133 - 139.

Afonso, A., Schuknecht, L., \& Tanzi, V. (2005). Public sector efficiency: an international comparison. Public Choice , 123 (3/4), 312-347.

Afonso, A. , Schuknecht, L. and Tanzi, V. (2008). Income Distribution Determinants and Public Spending Efficiency. Working Paper Series No 861. European Central Bank.

Afonso, A., Schuknecht, L. \& Tanzi, V.(2010). Public Sector Efficiency: Evidence for New EU Member States and Emerging Markets. Applied Economics, 42, 2147 - 2164.

Afonso, A.O., \& Alegre, J.G.A. (2011). Economic Growth and Budgetary Components: A Panel Assessment for the EU. Empirical Economics, 41(3),703-723.

Carboni, O.A. \& Medda, G. (2011). Government Spending and Growth in a Neoclassical Model. Math Finan Econ, 4(4), 269 - 285.

Chen, B.L. (2006). Economic Growth with an Optimal Public Spending Composition. Oxford Economic Papers, 58(1), 123 - 136.

Dutu, R. \& Sicari, P. (2016). Public Spending Efficiency in the OECD: Benchmarking Health Care, Education and General Administration. OECD Economics Department Working Papers. No, 1278.

Esanov, A. (2009). Efficiency of Public Spending in Resource-Rich Post-Soviet States. Revenue Watch Institute at https://resourcegovernance.org/sites/default/files/documents/rwi_esanov_efficiencyof publicspending.pdf

Fan, S. Hazell, P. \& Thorat, S. (2000). Government Spending, Growth and Poverty in Rural India. American Journal of Agricultural Economics, 82(4), 1038 - 1051.

Farrell, J. (1957). The measurement of productive efficiency. Journal of the Royal Statistical Society, 120(3), $253-290$.

Fonchamnyo, D.C. \& Sama, M.C. (2016). Determinants of Public Spending Efficiency in Education and Health: Evidence from Selected CEMAC Countries. Journal Economic Finance, 40, $199-210$.

Fox, K.J. (2002). Performance assessment in the public sector. In: KJ. Fox,ed., efficiency in the public sector. Boston: Kluwer Academic Publishers.

Gupta, S., \& Verhoeven, M. (2001). The efficiency of government expenditure: experiences from Africa. Journal of Policy Modeling, 23 (4), 433-467.

Hansson, P. \& Henrekson, M. (1994). A New Framework for Testing the Effect of Government Spending on Growth and Productivity. Public Choice, 81 (3/4), 381 401.

Hauner, D. abd Kyobe, A. (2008). Determinants of Government Efficiency. IMF Working Paper.

Herrera, S. \& G. Pang (2005). Efficiency of public spending in developing countries: An efficiency frontier approach. World Bank Policy Research Working Paper, No. 3645, World Bank, Washington DC.

Kimaro, E.L., Keong, CC \& Sea, LL (2017). Government Expenditure, Efficiency and Economic Growth: A Panel Analysis of Sub Saharan African Low Income Countries, African Journal of Economic Review, 5(2), 34 - 54.

Landau, D. (1986). Government and Economic Growth in the Less Developed Countries: An Empirical Study for 1960 - 1980. Economic Development and Cultural Change, $35(1), 35-75$.

Mandl, U., Dierx, A. and Ilzkovitz, F. (2008). The Effectiveness and Efficiency of Public Spending. Economic Paper 301. European Commission. 
Moreno-Enguix, M.D. R. \& Bayona, L.V.L. (2017). Factors Affecting Public Expenditure Efficiency in Developed Countries. Politics and Policy, 45(1), $105-143$.

Odhiambo, NM (2015). Government Expenditure and Economic Growth in South Africa: An Empirical Investigation. Atlantic Economic Society, 43(3), 93 - 406.

Ouertani, M.N., Naifar, N. and Haddad, H.B. (2018). Assessing Government Spending Efficiency and Explaining Inefficiency Scores: DEA-Bootstrap Analysis in the Case of Saudi Arabia. Cogent Economics and Finance, 6 (1), 1 - 16.

Salih, M.A.R. (2012). The Relationship between Economic Growth and Government Expenditure: Evidence from Sudan. International Business Research, 5(8), 40 - 46.

Saunders, P. (1985). Public Expenditure and Economic Performance in OECD Countries. Journal of Public Policy, 5(1), 1 - 21.

Taiwo, M. and Abayomi, T. (2011). Government Expenditure and Economic Development: Empirical Evidence from Nigeria. European Journal of Business and Management, $3(9), 18-28$.

Tanzi, V., and Schuknecht, L. (2000). Public spending in the 20th century: A Global Perspective.Cambridge: Cambridge University Press.

Wang, E.C. and Alvi, E. (2011). Relative Efficiency of Government Spending and Its Determinants: Evidence from East Asian Countries. Eurasian Economic Review, 1(1), $3-28$.

Wu, S. Y., Tang, J.H. and Lin, E.S. (2010). The Impact of Government Expenditure on Economic Growth: How Sensitive to the Level of Development?. Journal of Policy Modelling, 32 (6), $804-817$.

Xu, K., Evans, D.B., Kawabata, K., Zeramdini, R., Klavus, J. and Murray, C.J.L. (2003). Household Catastrophic Health Expenditure: A Multicountry Analysis. The Lancet, $362,111-117$. 